
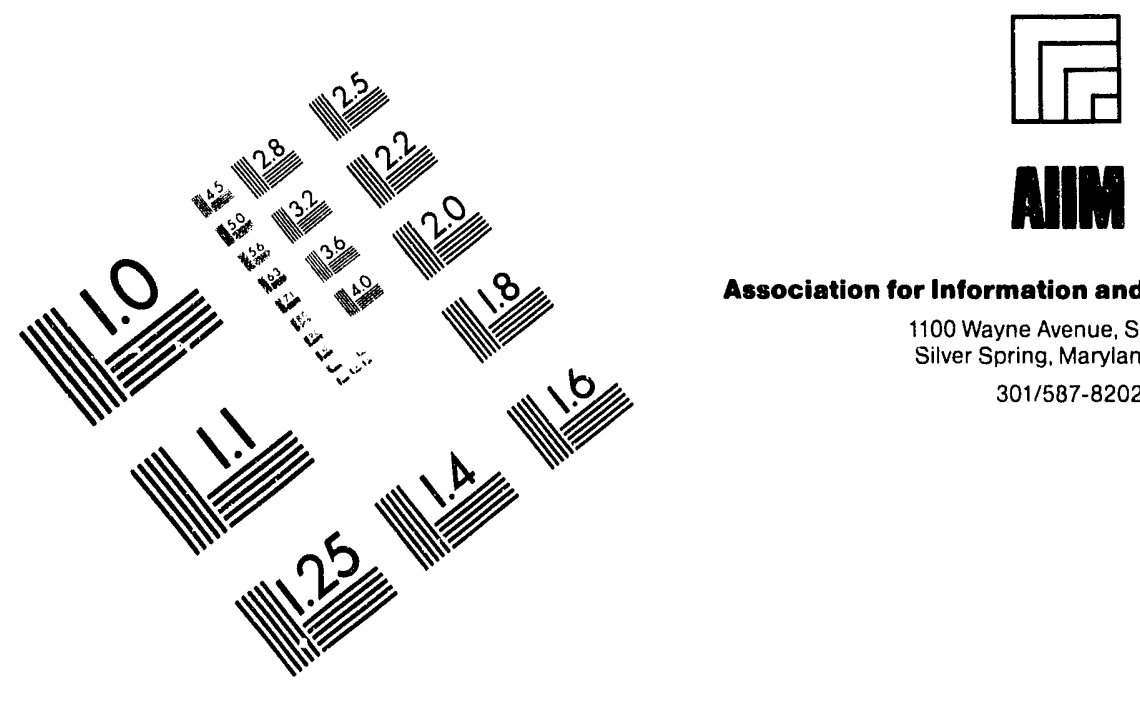

Association for Information and Image Management

1100 Wayne Avenue, Suite 1100

Silver Spring. Maryland 20910

$$
\text { 301/587-8202 }
$$

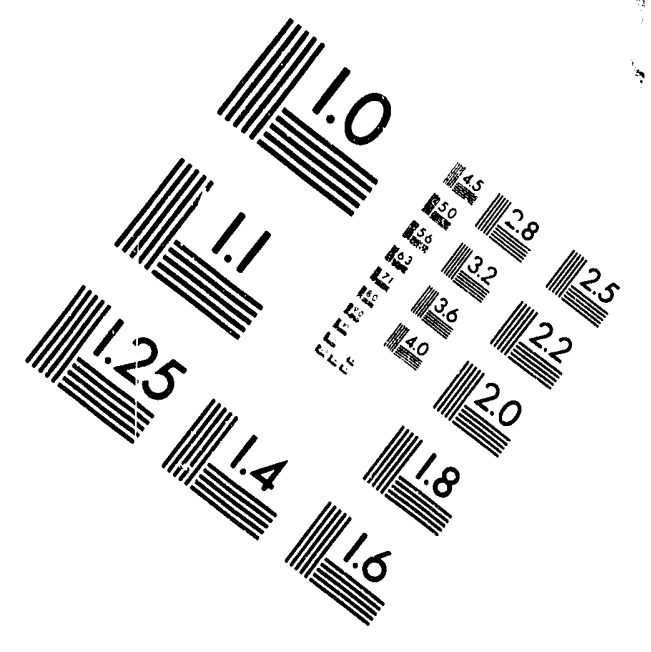

\title{
Centimeter
}

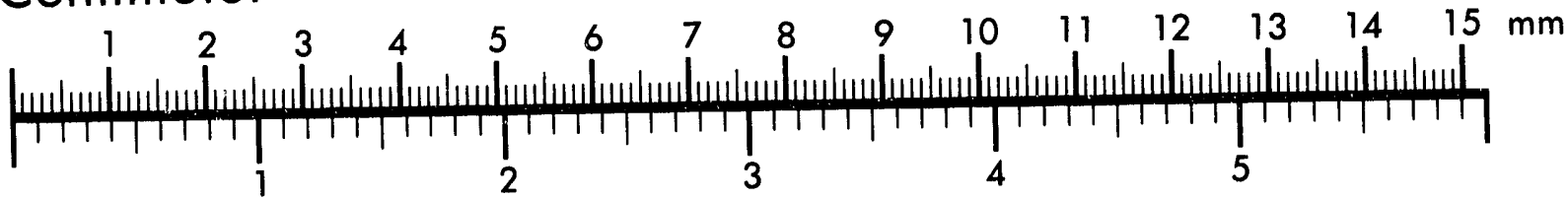
Inches
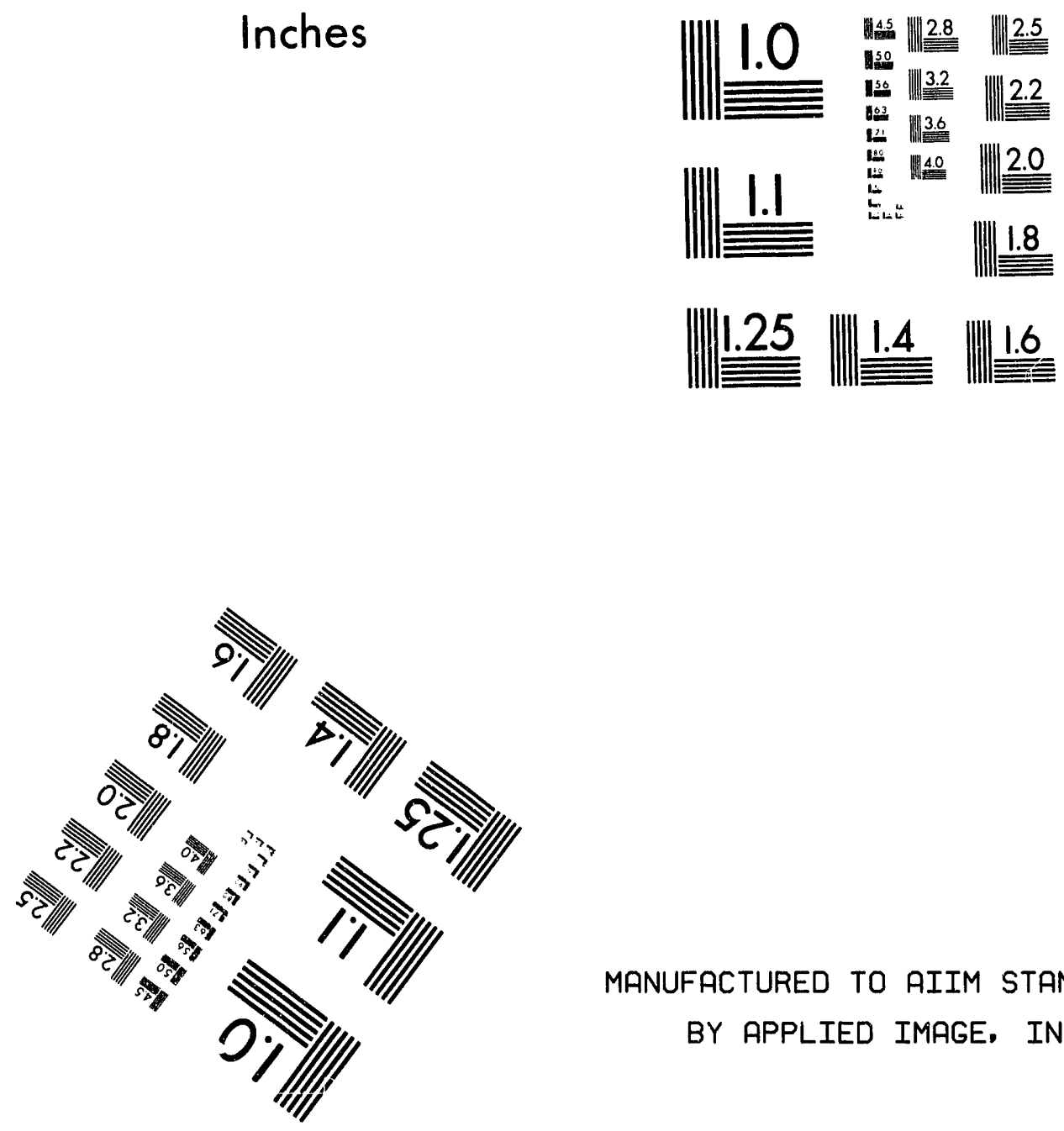

MANUFACTURED TO AIIM STANDARDS

BY APPLIED IMAGE, INC.

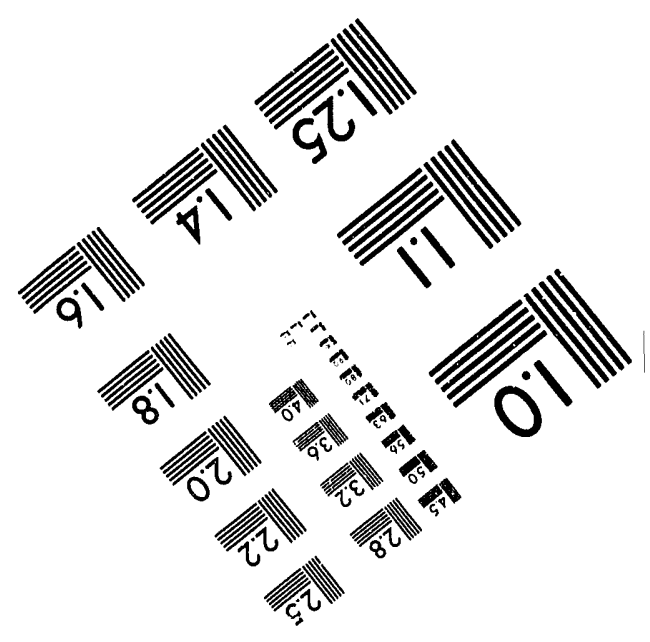



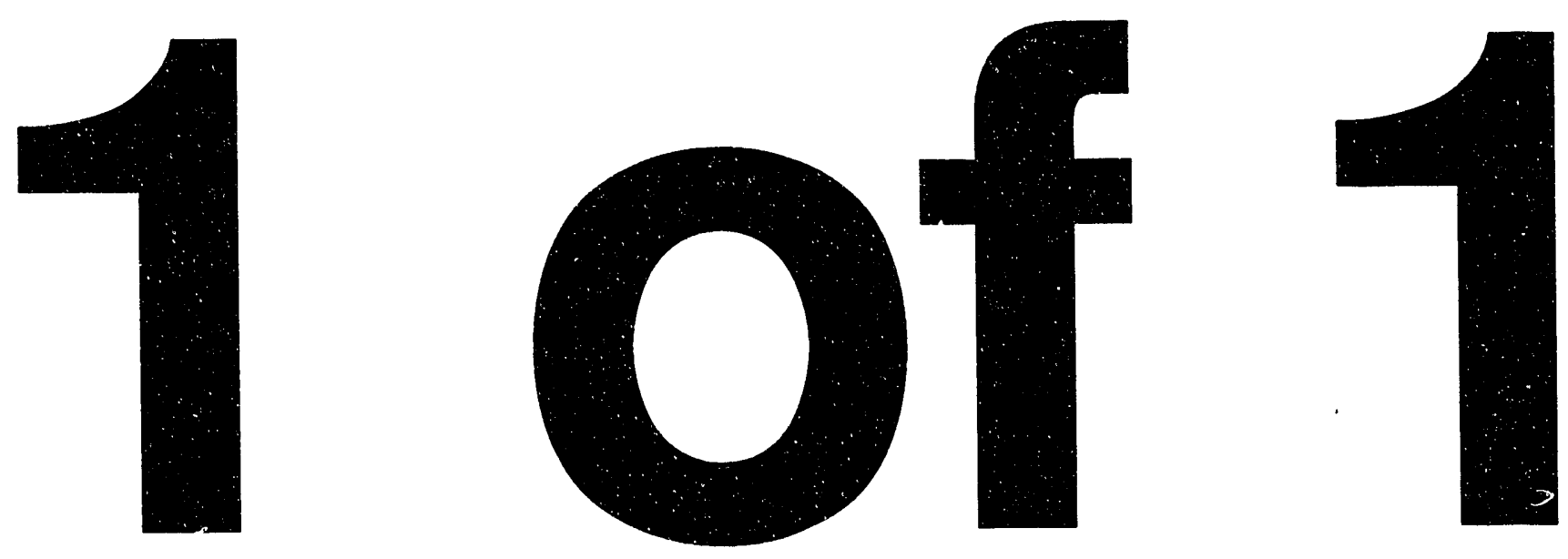


\section{GROWTH CURVE ANALYSIS FOR PLASMA PROFILES USING SMOOTHING SPLINES}

Annual Progress Report
for Period June 1992 to June 1993 Maya Imre
City University of New York
College of Staten Island
May 1993
Prepared for

NOTICE

This report was prepared as an account of work sponsored by the United States Government. Neither the United States nor the Department of Energy, nor any of their employees, nor any of their contractors, subcontractors, or their employees, makes any warranty, expressed or implied, or assumes any legal liability or responsibility for the accuracy, completeness, or usefulness, of any information, apparatus, product or process disclosed or represents that its use would not infringe privately-owned rights.

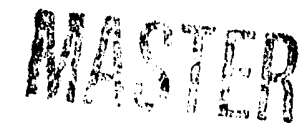




\section{ABSTRACT}

We are developing a profile analysis code for the statistical estimation of the parametric dependencies of the temperature and density profiles in tokamaks. Our code uses advanced statistical techniques to determine the optimal fit, i.e. the fit which minimized the predictive error. For a forty TFTR Ohmic profile dataset, our preliminary results indicate that the profile shape depends almost exclusively on $q_{a}$, but that the shape dependencies are not Gaussian. We are now comparing various shape models on the TFTR data. In the first six months, we have completed the core modules of the code, including a B-spline package for variable knot locations, a data-based method to determine the optimal smoothing parameters, self-consistent estimation of the bias errors, and adaptive fitting near the plasma edge. Visualization graphics already include three dimensional surface plots, and discharge by discharge plots of the predicted curves with error bars together with the actual measurements values, and plots of the basis functions with errors.

\section{INTRODUCTION}

We are generalizing empirical scalings from a single performance parameter, such as the energy confinement time, to an unknown function such as the temperature profile. We assume that the dependence of the temperature on the plasma parameters can be represented as, $c f$. Refs 1-4,

$$
T\left(r, q_{a}, \bar{n}, P, B_{t}\right)=Y_{0}(r)+Y_{1}(r) q_{a}+Y_{2}(r) \ln \bar{n}+\ldots
$$

where $r, q_{a^{\prime}}, \bar{n}, P, B_{t}$ denote the normalized flux radius, the safety factor, line averaged density, absorbed power, and toroidal magnetic field, respectively. In practice, we replace the temperature/density profile with its logarithm. The Tang and Redi (cf. Refs. $5,6)$ profile consistency model is of this general class, as are a number of other profile "resilience" models. In most of these phenomenological models, the profile functions, $Y_{i}(r)$, are arbitrarily specified to be Gaussians. In contrast, we estimate these profile functions empirically using penalized regression analysis, cf. Ref.7. As a results, we have a profile model which fits the data much better.

This type of profile analysis has four main advantages:

1. The signal to noise ratio is increased by analyzing many discharges simultaneously.

2. The systematic trends in profile variation are easily recognized and quantified. 
3. The fitted profiles may be used to analyze these systematic trends in power balance and stability codes, and to extrapolate plasma performance into unexplored regions in parameter space.

4. Because our parameterized profiles average over the discharge to discharge variability, our results are automatically more generic.

Of particular interest is to predict the radial distribution of fusion power output in the tritium discharges in TFTR and JET.

In the next section, we report on our progress in these three areas, model development, experimental testing and comparisons, and code development. In the third section, we describe our work plan for the next 18 months. Our basic method for fitting plasma profiles has been described in detail in both March 1992 proposal, and in a recently accepted article. We attach copies of both.

The last sections list the documentation of our work in refereed journals and conferences. We also present our budget for the next year.

\section{RESEARCH PROGRESS}

\section{a) Experimental Analysis}

We are completing our analysis of forty profile TFTR ohmic dataset. We have shown that the TFTR data set is best fit by a model of the form

$$
\ln T\left(r, q_{a^{\prime}} \bar{n}, P, B_{t}\right)=f_{0}(r)+f_{q}(r)\left(q_{a}-\bar{q}_{a}\right)+c_{B}\left(B_{t}-\bar{B}_{t}\right)+c_{n} \ln (\bar{n} / \overline{\bar{n}})
$$

where superscript bars represent the mean values. Thus the magnetic iield and density affect only the magnitude and not the shape. Figures $1 \mathrm{a}$ and $1 \mathrm{~b}$ plot the estimated functions $\exp \left(f_{0}(r)\right)$ and $\exp \left(f_{q}(r)\right)$ with error bars. Our results confirm earlier studies (cf. Refs.8,9) that the TFTR Ohmic profile shape depends almost exclusively on $q_{a}$. Our statistical analysis has given quantitative estimates of these dependencies and the associated error bars. Figure 2 presents a three dimensional surface plot of the fitted profile: $\hat{T}\left(r, q_{a}\right) ; B_{t}=4.65 \mathrm{~T}, \bar{n}=2.34 \times 10^{19} \mathrm{~m}^{-3}$. Clearly neither the mean profile, $f_{0}(r)$, nor the $q$ dependence shape factor, $f_{q}(r)$, are Gaussian in nature. Thus the more general spline fit is critical to a successful analysis of the data.

Figure 3 presents the fitted curves for each of the forty profiles along with the associated one sigma error bars and the measured data. The error bars are for the fitted curves. The total discrepancy between the measurement and fitted curve is measurement error plus the error in the fitted curve. In several of the discharges, there 
is a small systematic misfit between the fitted curve and the measured data. This occurs for three reasons: a) the model in Eq.(2) is only an approximation, b) discharge to discharge variation, and c) some of the discharges (particularly \#34 and \#36) appear to be systematically different than the rest of the data set. We hope to complete our analysis of this TFTR dataset in the next several months.

\section{b) Model Generalizations}

We have generalized the model presented in Eq. (2) to the case where one or more of the functions have a specified functional form. Previously, a model such as Eq.(2) required an arbitrary function for $f_{B}(r)$ and $f_{n}(r)$. Presently we are able to impose constants or Gaussian shapes. Thus we are able to examine the Tang-Redi model. We have also described a general procedure for extending our analysis to anomalous heat diffusivity parameterization.

\section{c) Code Developments}

We have developed a general purpose profile analysis code with the following special features:

1. Arbitrary knot spacing with data-based determination of good knot locations for a given dataset.

2. Nonuniform weighting of data points to account for larger experimental errors near the edge.

3. Arbitrary numbers of spline functions and parametric functions allowed.

4. Each spline function has its own smoothness parameter, and these parameters are determined from the data.

5. Self-consistent estimation of systematic bias due to smoothing.

6. Graphical outputs include three dimensional plots of fitted surface, plots of fitted $f_{i}(r)$ with error bars, and residual error plots.

Much of the development time was spent in three areas: a) adding tuning parameters to improve the fit to the plasma edge, b) implementing multiple smoothing parameters, c) adding parametric basis functions. The core modules of the code are virtually complete. 


\section{PROPOSED WORK}

\section{a) Experimental Analysis}

We are completing arrangements to begin an active collaboration with JET (Cordey's Group) in conjunction with Dr. K. Riedel. We anticipate that our joint work will result in the first ever parameterization of the JET profile shapes. We will document our work in a published article and will assure that the results are in a form which can be used in ITER design. (This commitment is conditional on JET approval of publication of our results.) We will also actively seek collaborations with TFTR and D3D; particularly attractive options are a D3D-JET profile comparison with extrapolations to ITER, and D-T extrapolations for JET and TFTR.

In the initial phase of this work, we have concentrated, and will concentrate, on identifying the parametric dependencies on the temperature and density profiles. In the next year, we plan to begin the other goal: magnetic island identification. As shown in our initial proposal, we can identify the local flattenings of the temperature profile, cf. Ref.10-11. Furthermore, we can estimate the error bars in the inferred temperature gradient.

\section{b) Code Developments}

\section{1) Model testing and bias estimation}

Currently, we accurately estimate the bias error associated with smoothing the data, but we do not accurately account for bias error associated with model misspecification. To test models like Tang-Redi statistically, we need to include the model misspecification error. We have begun formulating empirical estimates of this term.

\section{2) Random intercept models for discharge variations}

A large portion of the error in fitting multiple profiles is from errors in the profile magnitude. Thus the profile shape is estimated more accurately than the magnitude. As a result, the residual fit errors are correlated. We propose to use a random intercept model to account for the variability of the temperature magnitude. Such models have been used with success in confinement time analysis.

\section{3) User interface}

After thoroughly testing our code on a number of characteristic tokamak datasets, we plan to develop a user friendly version of the profile parameterization code. In the long run, we hope to have an interactive interface with graphics. 


\section{Publications and Conferences}

1. K.S. Riedel and Kaya Imre, Smoothing Spline Growth Curves with Covariates, accepted for publication in Comm. in Statistics.

2. Kaya Imre and K.S. Riedel, A Hierarchy of Plasma Transport Models, in progress

3. Kaya Imre and K.S. Riedel, Smoothing Spline Analysis of Plasma Profiles, presented at 34th Annual Meeting Division of Plasma Physics, Seattle, WA, Nov. 16-20, 1992

4. Kaya Imre and K.S. Riedel, Smoothing Spline Analysis of Plasma Profiles, presented at Sherwood Theory Conference, Newport, RI, March 28-31, 1993

5. Kaya Imre and K.S. Riedel, Smoothing Spline Growth Curves with Covariates, presented at the Joint Meeting with the Institute of Mathematical Statistics and the American Statistical Association, Philadelphia, PA, March 21-24, 1993.

\section{Computational Facilities}

Much of the work will be done at the Courant Institute of Mathematical Sciences, of New York University, where office space has been provided. Access to various workstations and to NERSC Cray machines are also provided. In addition, a new personal computer with a $80486 / 66 \mathrm{CPU}$ is being purchased by NYU for this project.

\section{REFERENCES}

1. K.S. Riedel and Kaya Imre, "Smoothing Spline Growth Curves with Covariates", accepted for publication in Comm. in Statistics.

2. Kaya Imre and K.S. Riedel, "A Hierarchy of Plasma Transport Models", in progress

3. P.J. McCarthy, K.S. Riedel, O.J.W.F. Kardaun, H. Murmann, K. Lackner, "Scaling and Plasma Profile Parameterization of ASDEX High Density Ohmic Discharges", Nuclear Fusion, 31, 1595(1991)

4. O.J.W.F. Kardaun, K.S. Riedel, P.J. McCarthy, K. Lackner "A Statistical 
Approach to Plasma Profile Analysis", Max-Planck Institut fur Plasmaphysik, Report No: IPP 5/35, May 1990.

5. W.M. Tang, Nuclear Fusion, 26, 1605(1986).

6. M.H. Redi, W.M. Tang, P.C. Efthimion, et al., Nuclear Fusion, 27, 2001(1987).

7. P. Craven and G. Wahba, "Smoothing Noisy Data with Spline Functions: Estimating the Correct Degree of Smoothing by the Method of Generalized Cross-validation", Numer. Math., 31, 377(1979).

8. V.D. Arunsalam, N.L. Betz, P.C. Efthimion, et al., Nucl. Fusion, 30, 2111(1990).

9. A. Hiroe, et al., "Scale length study in TFTR", PPPL Report No. 2576(1988).

10. B. Grek, D. Johnson, G. Taylor, E. Fredrickson, "Large scale Fluctuations and Transport on TFTR", Bull. Am. Ph. Soc., 36, 2378(1991).

11. H-G. Muller, "Kernel Estimators of Zeros and of Locations and Size of Extrema of Regression Functions", Scan. J. Statist., 12, 221(1985). 

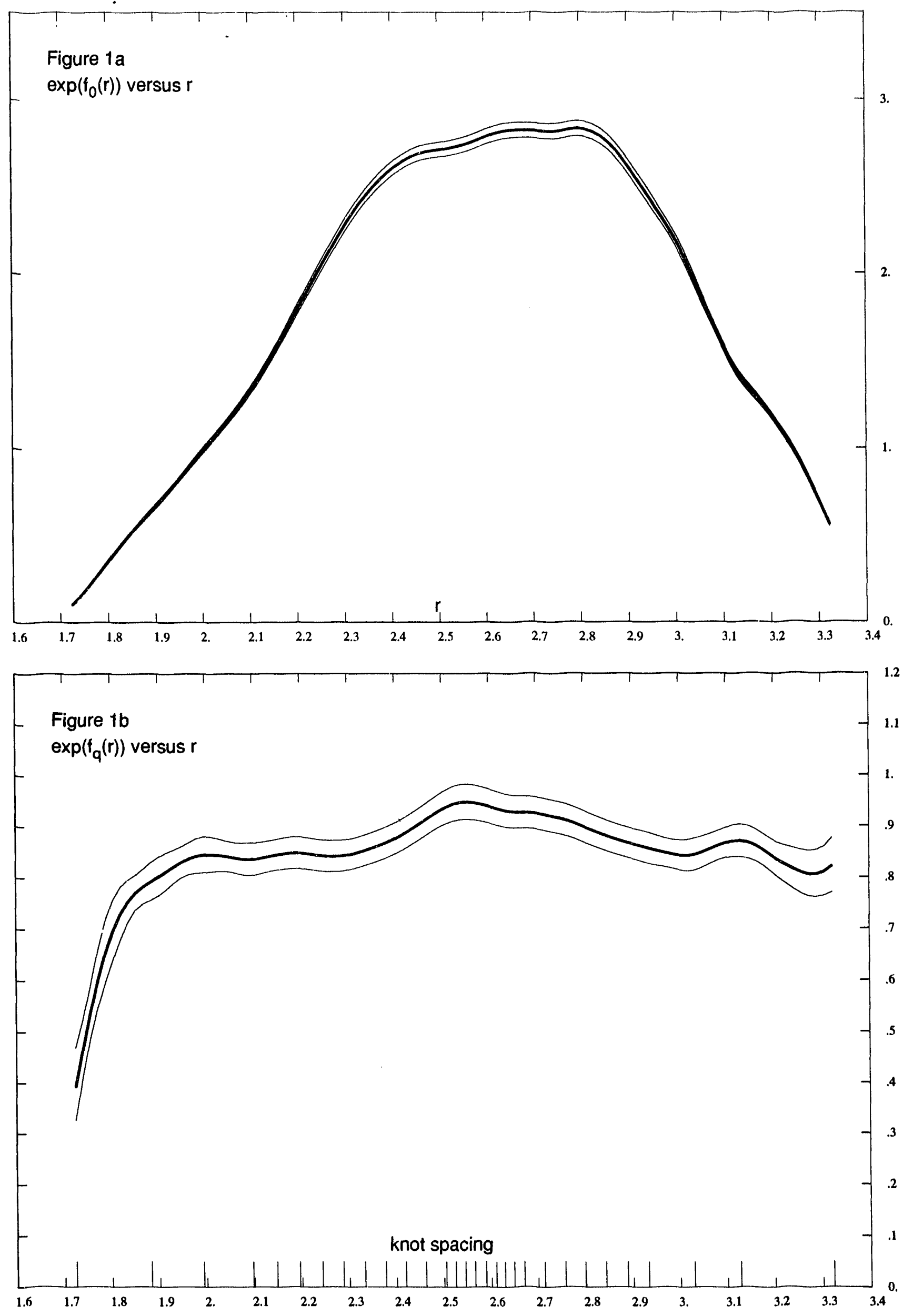


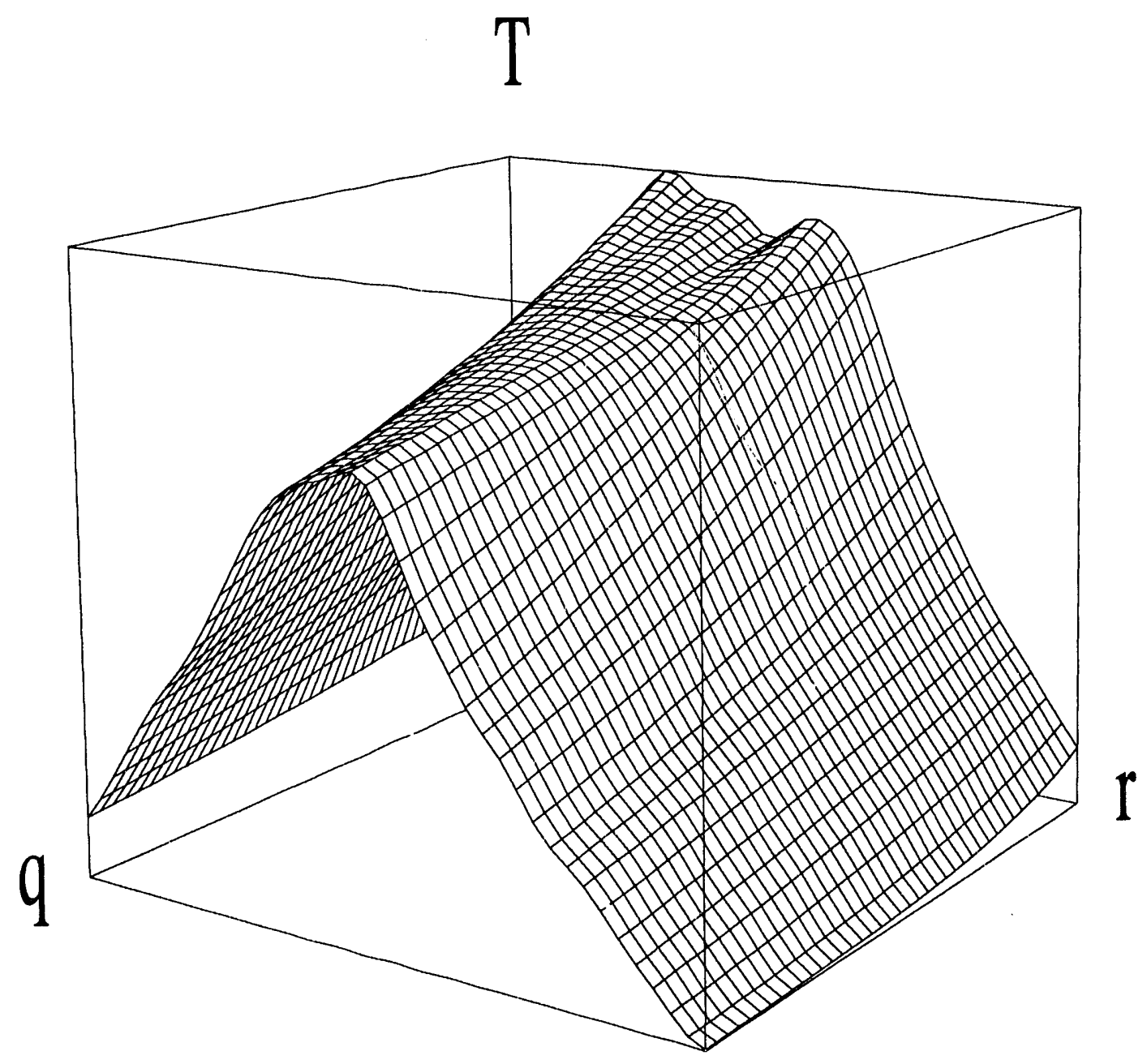

Figure 2

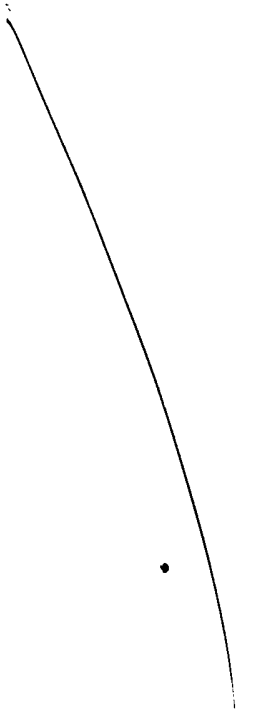



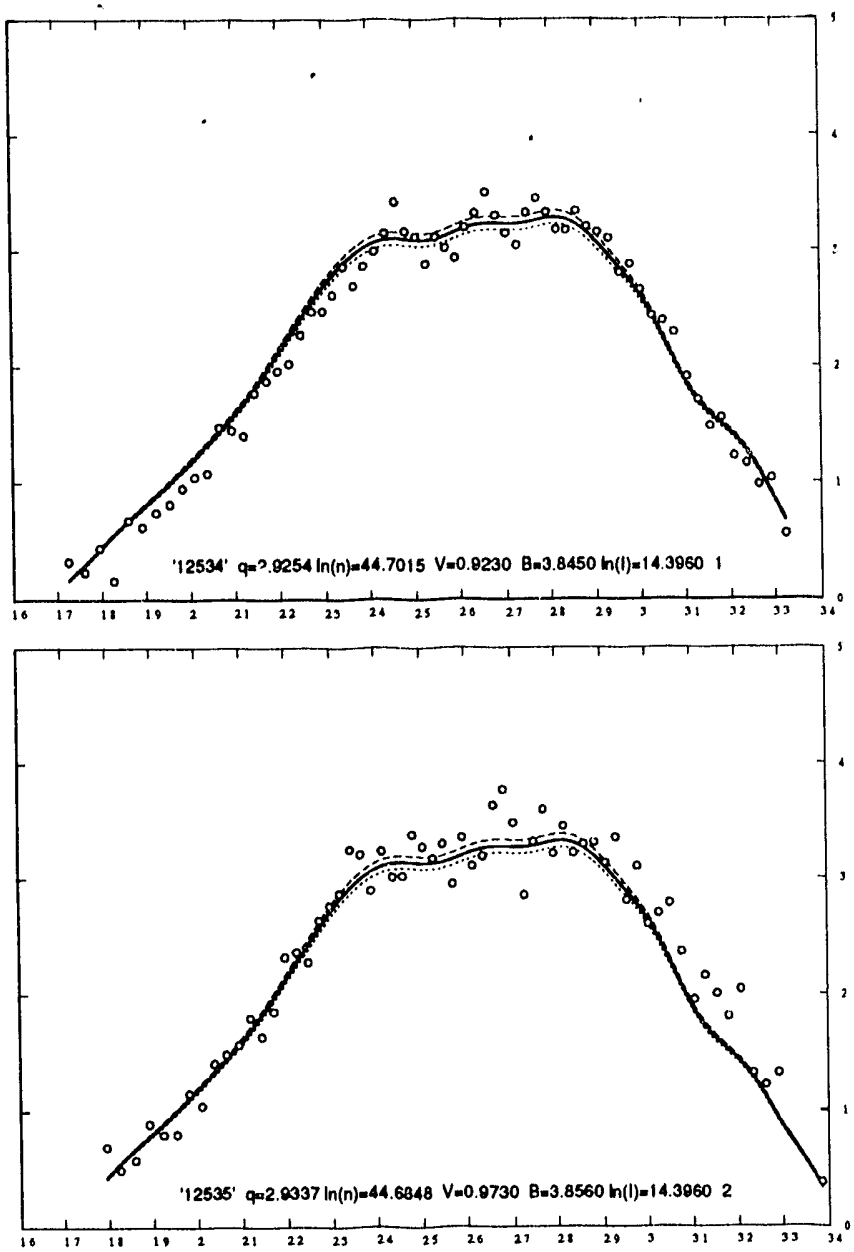
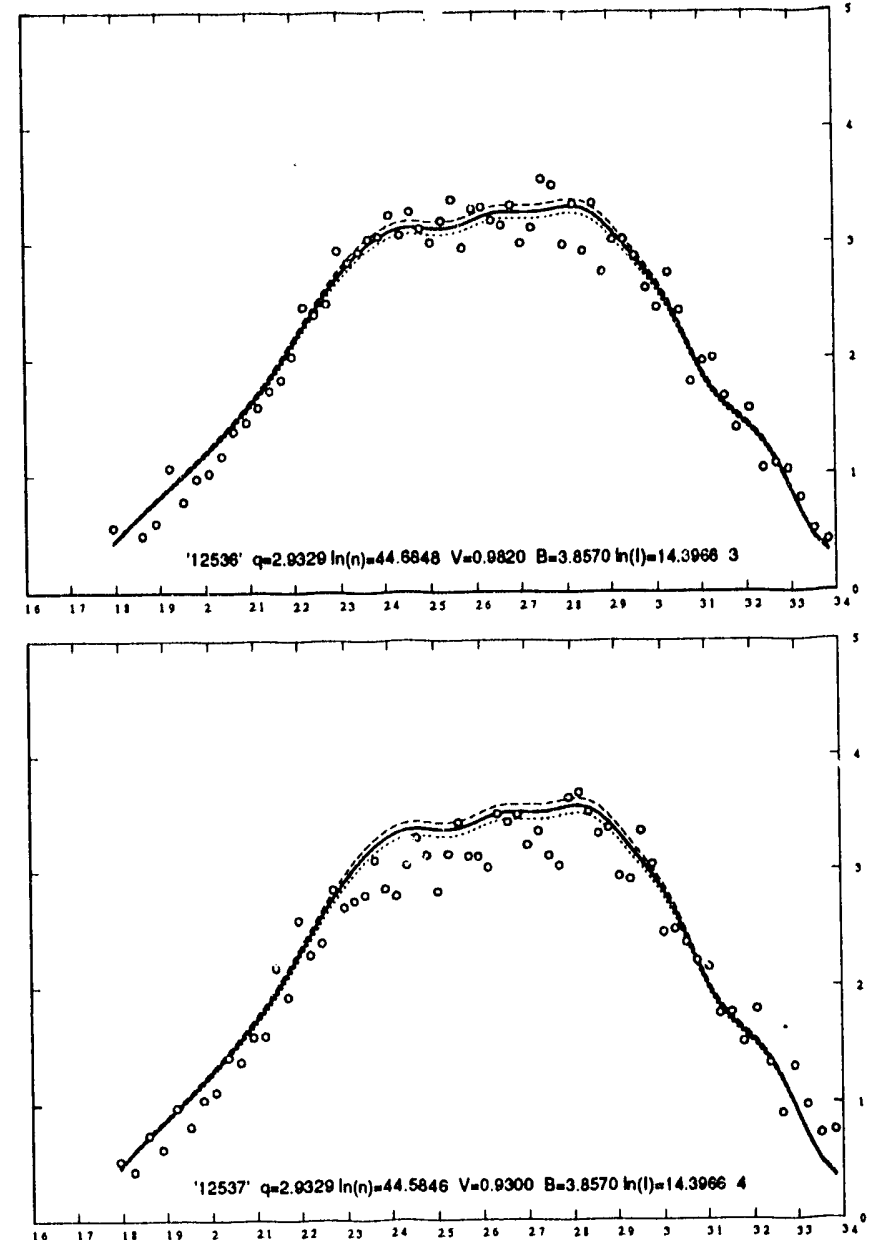

Figure $3 a$
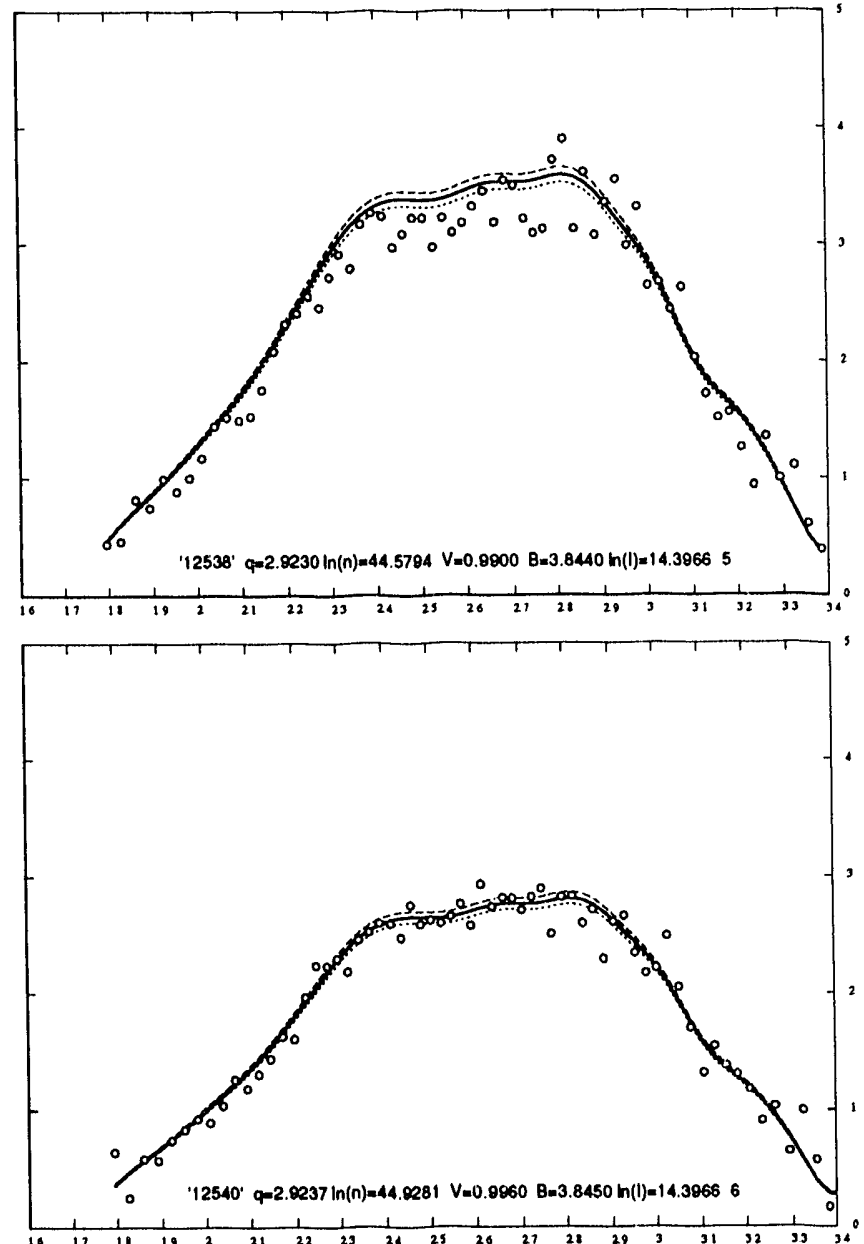
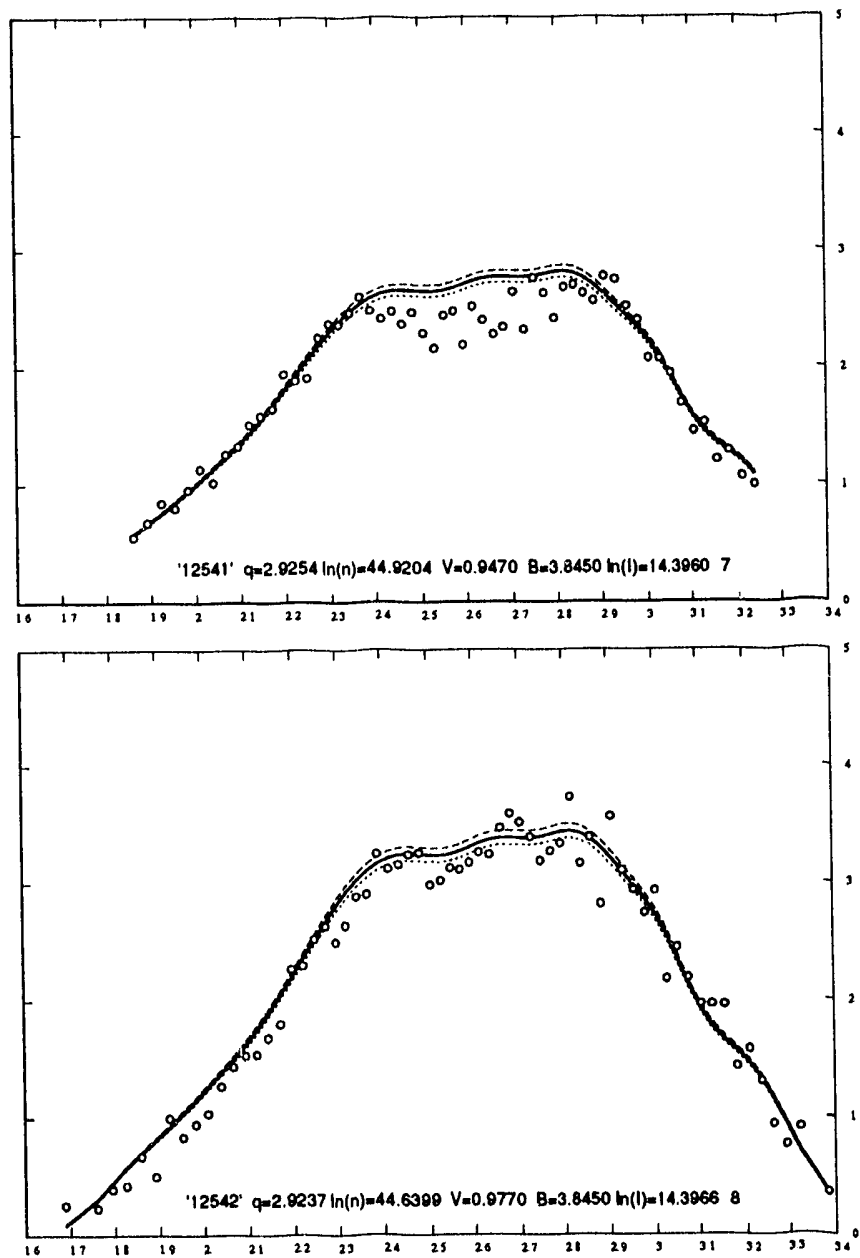

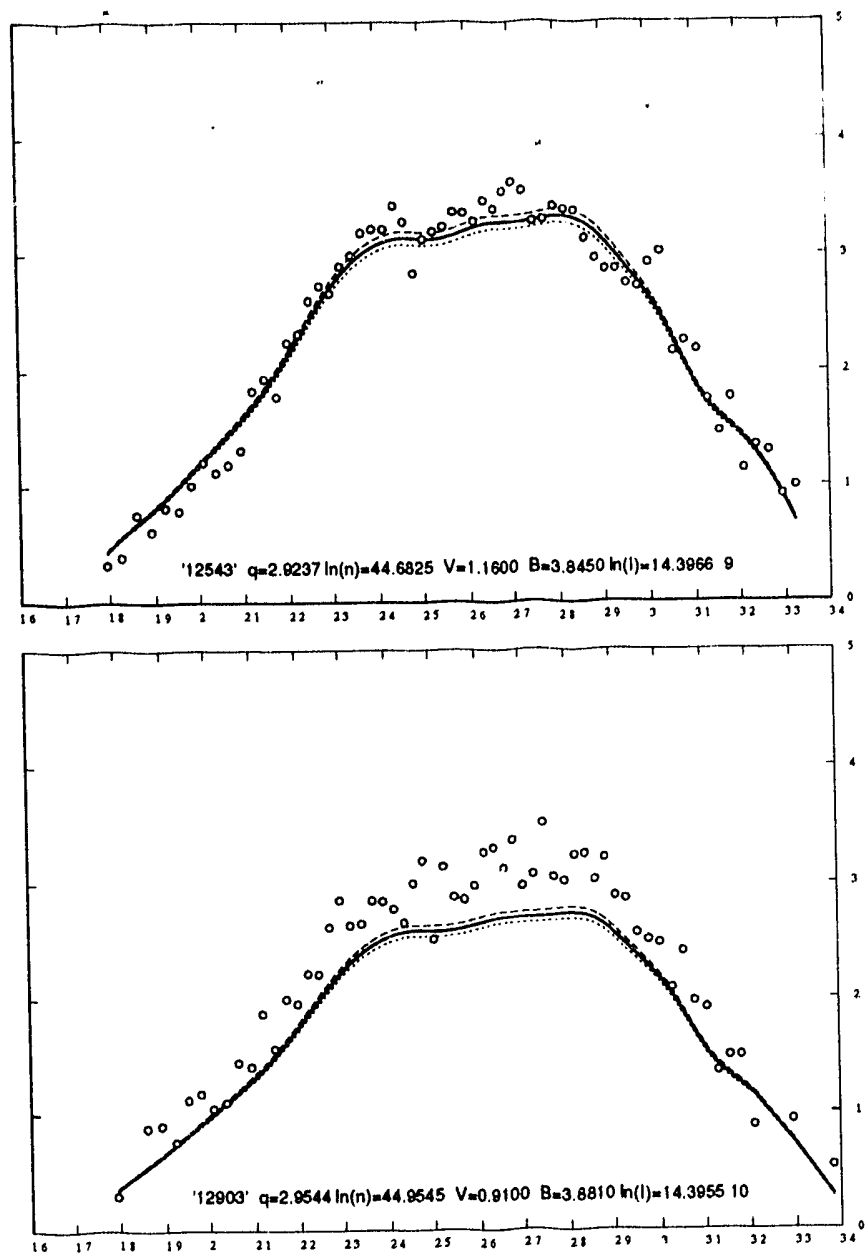
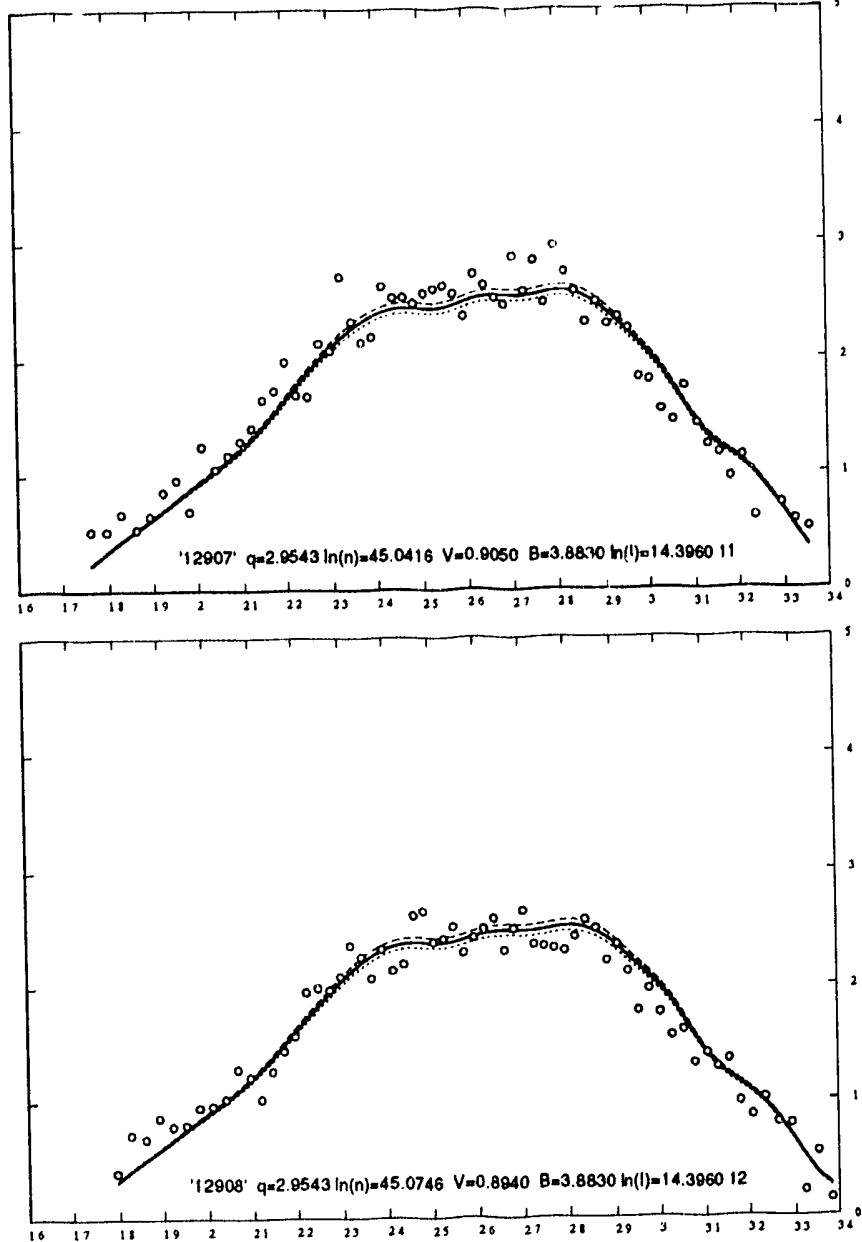

Figure $3 b$
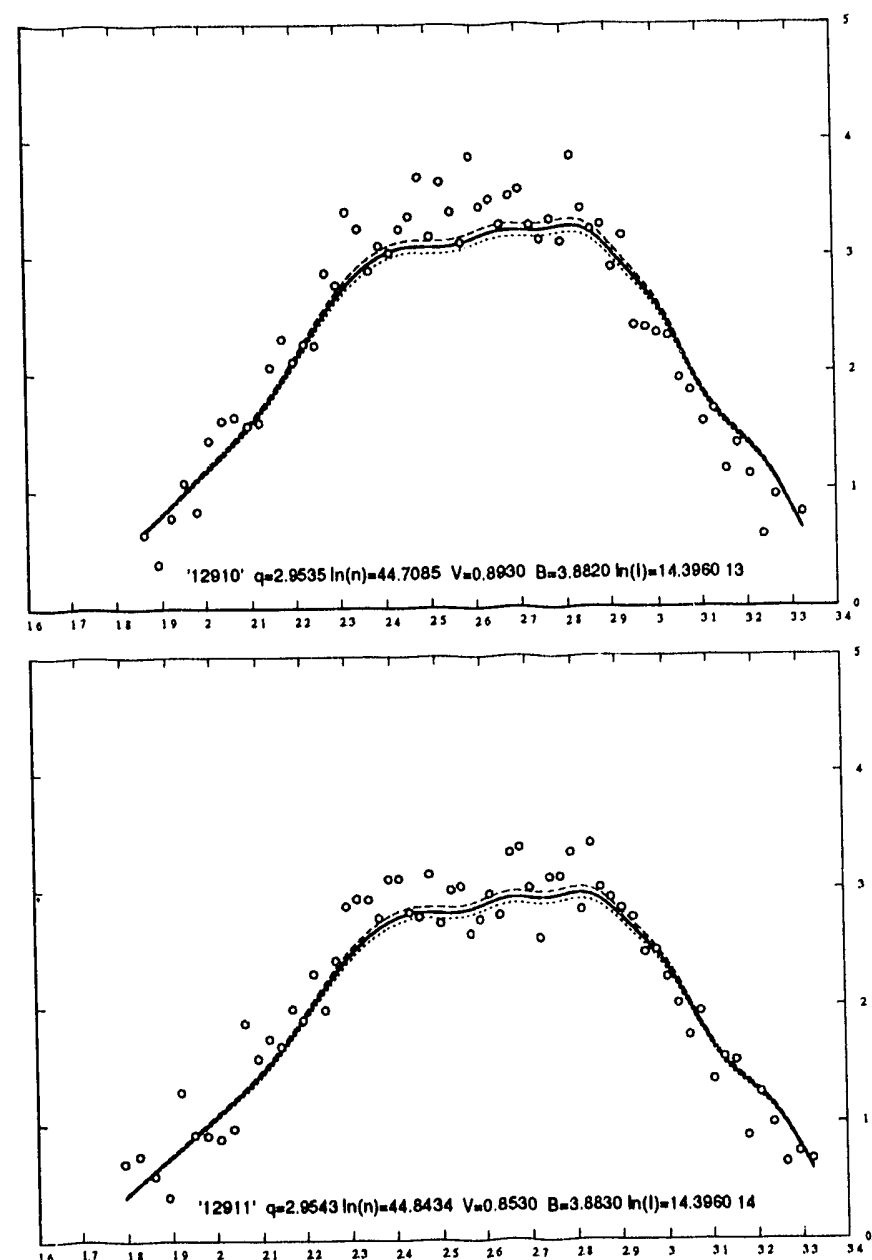
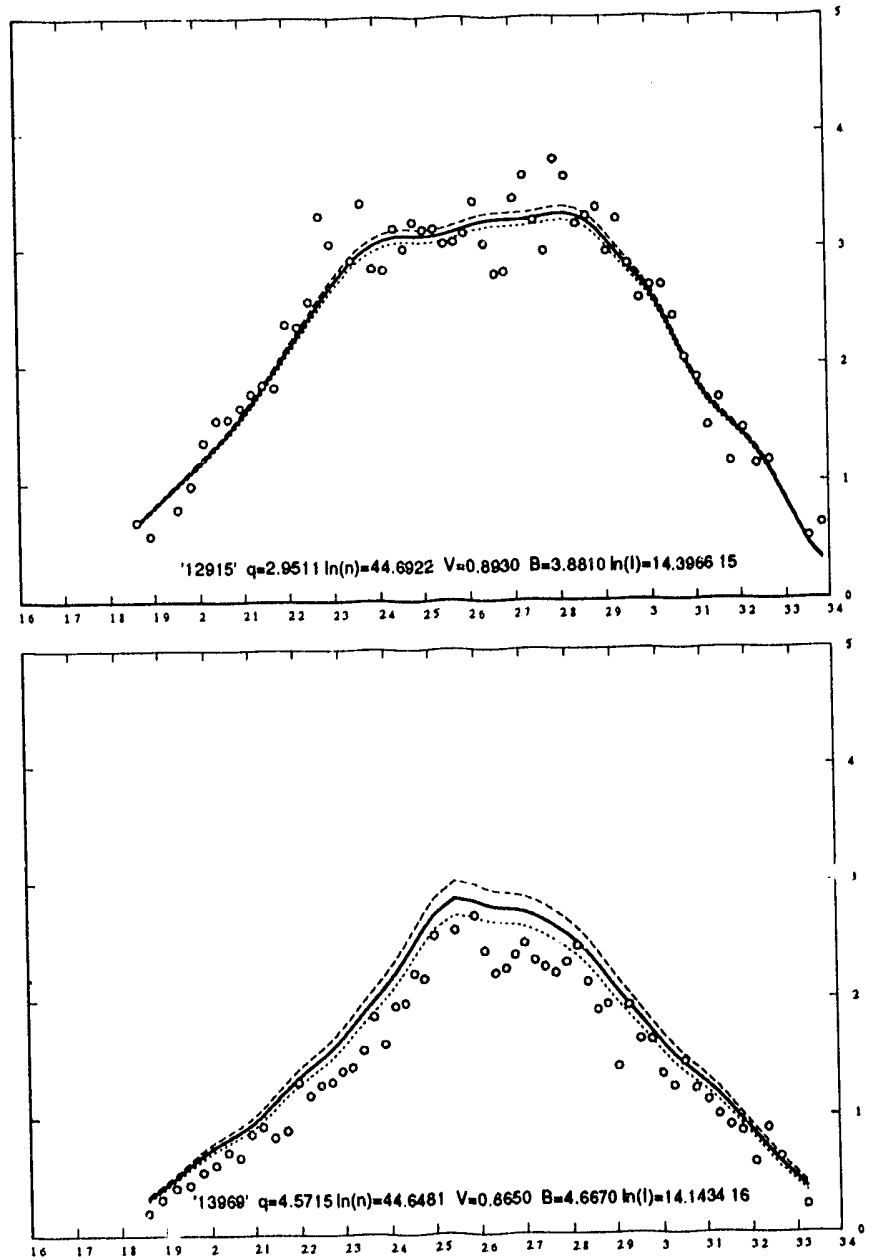

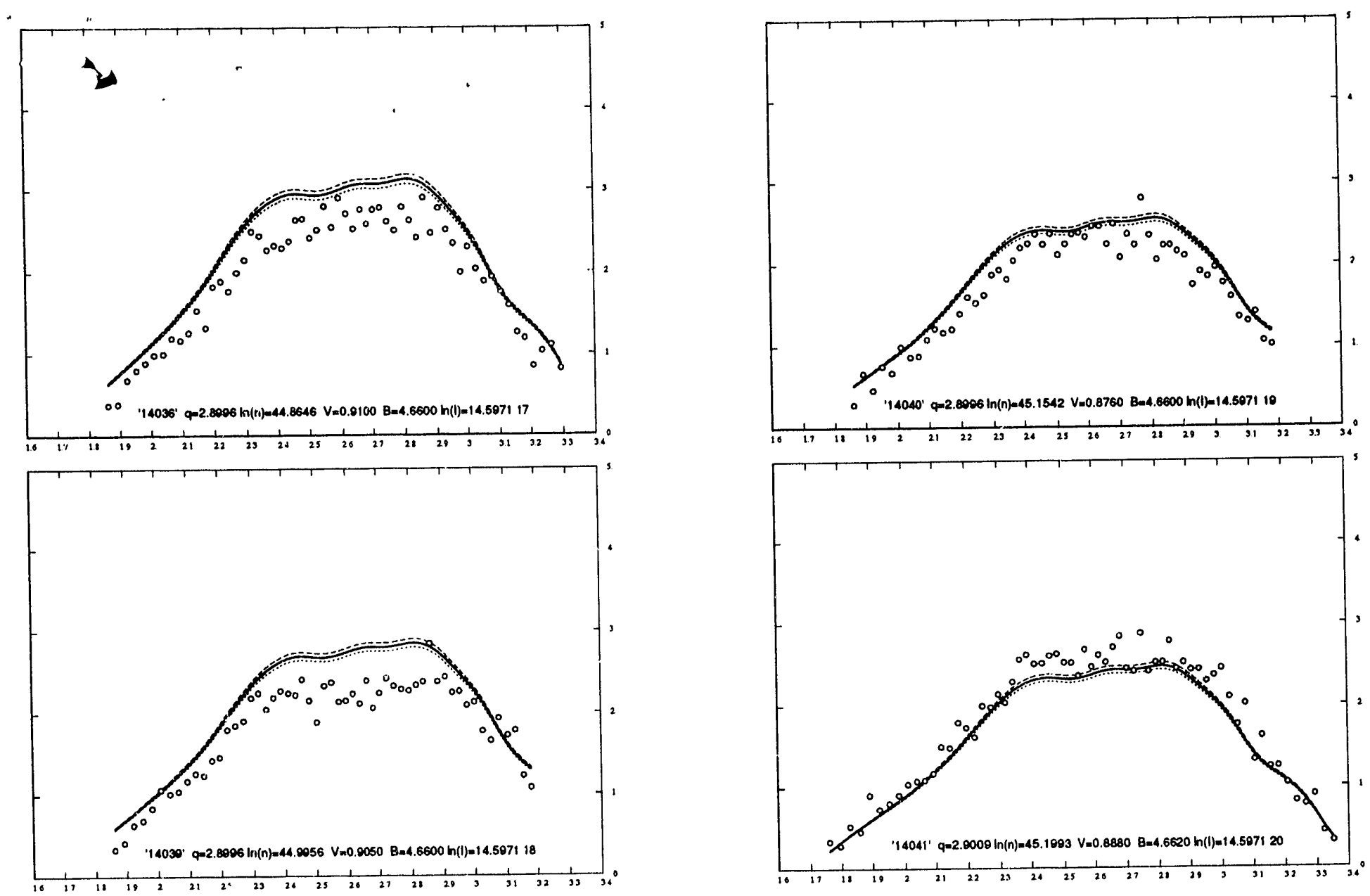

Figure $3 \mathrm{c}$
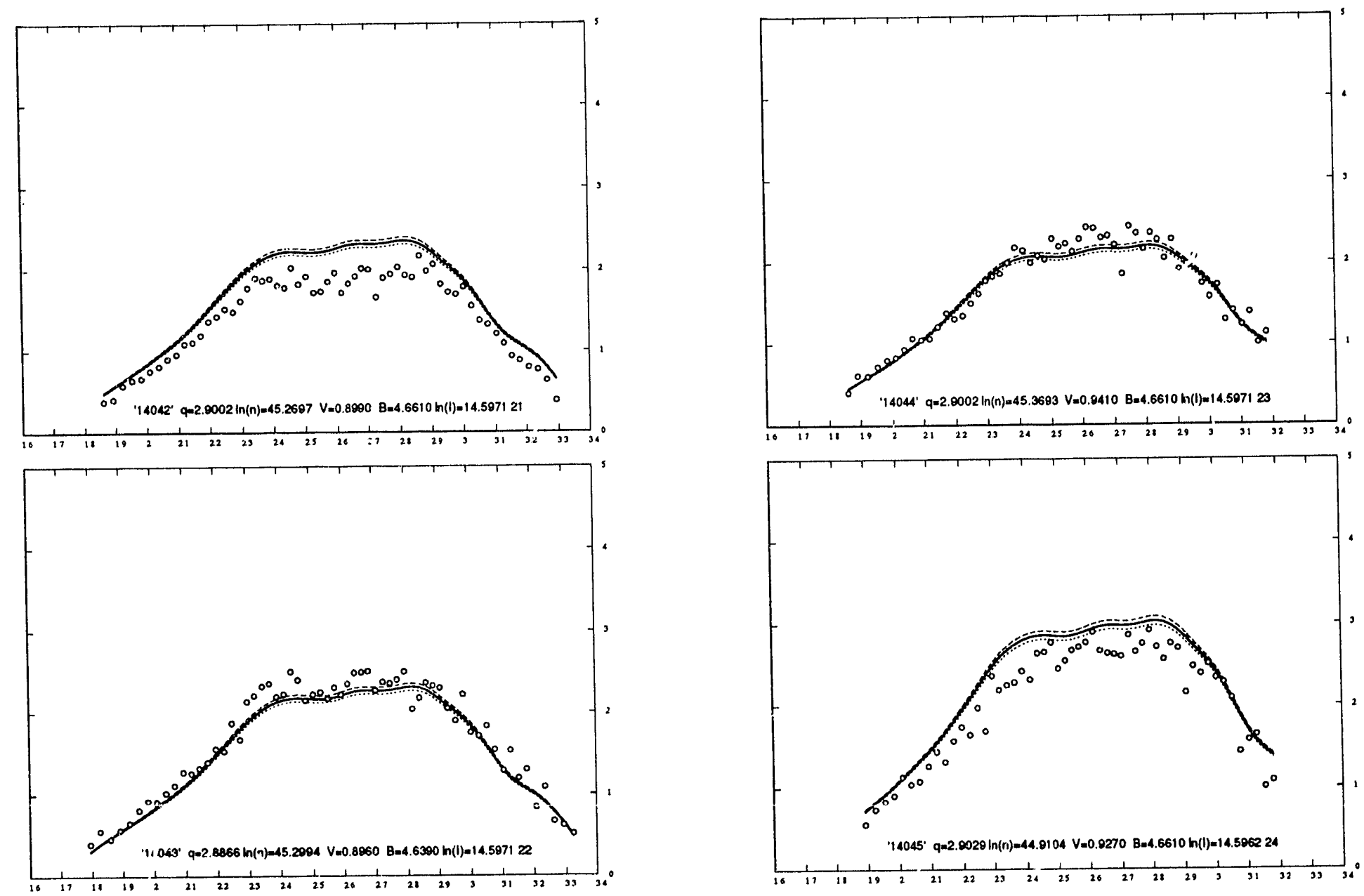

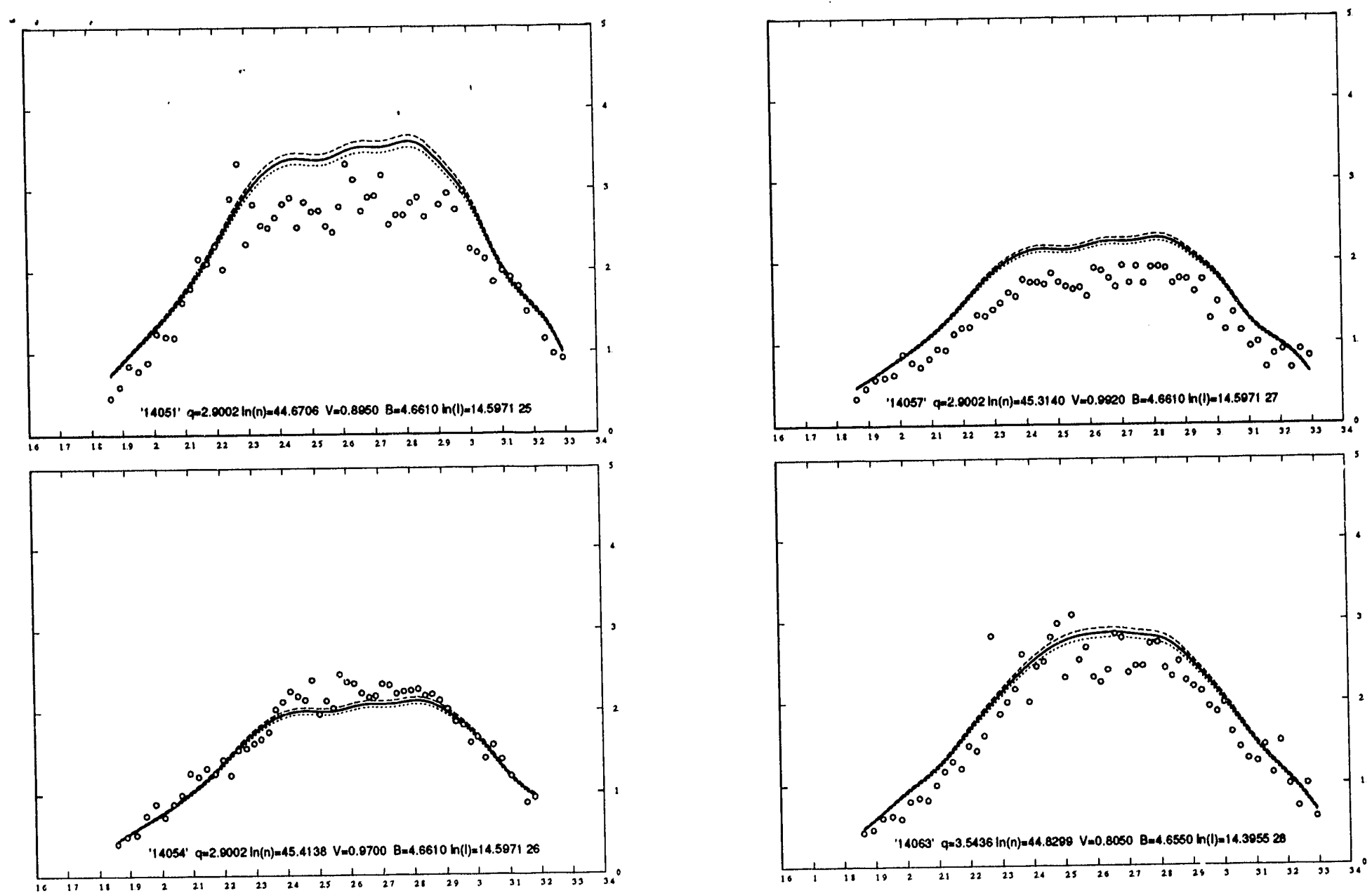

Figure 3d
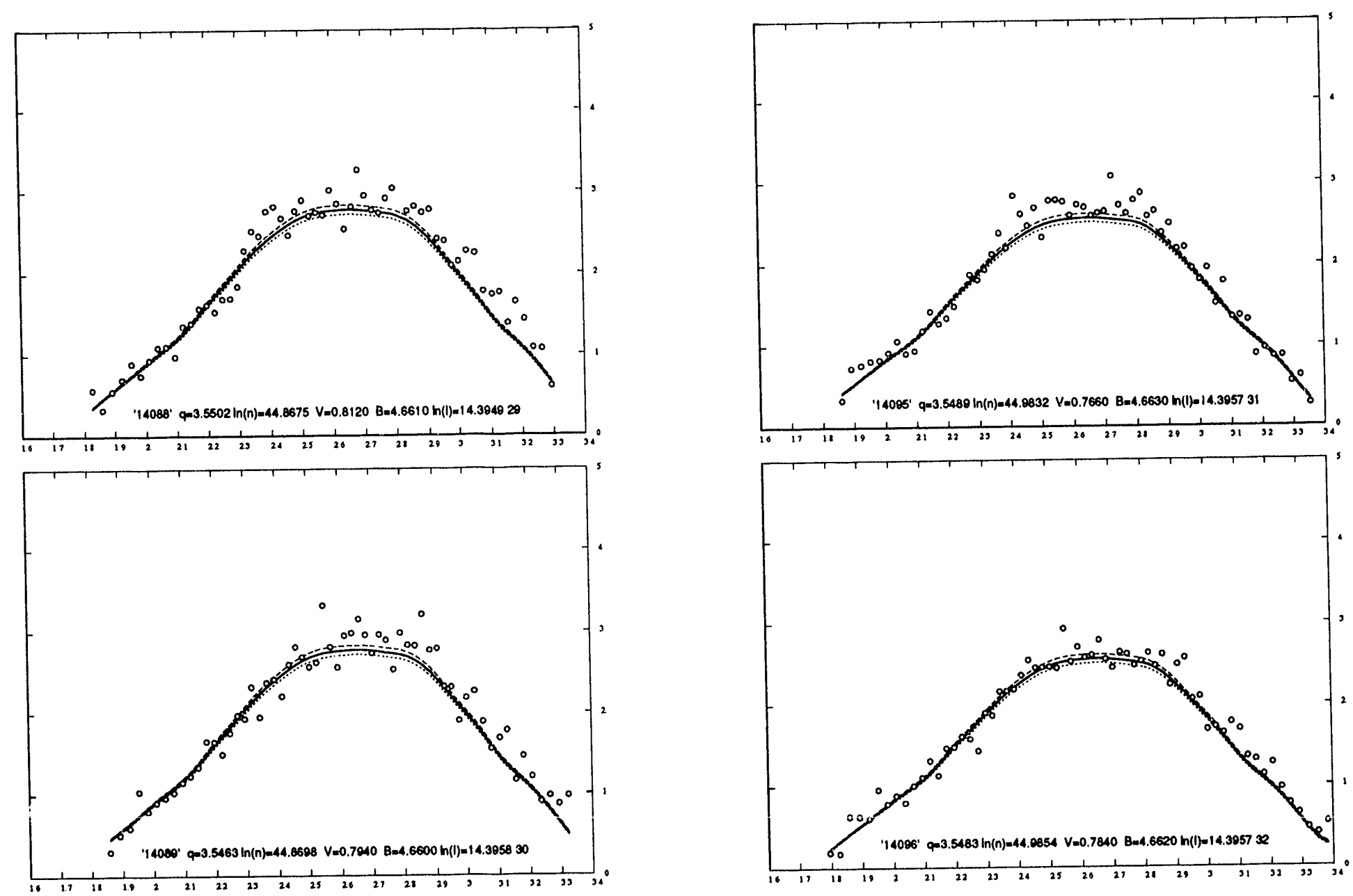

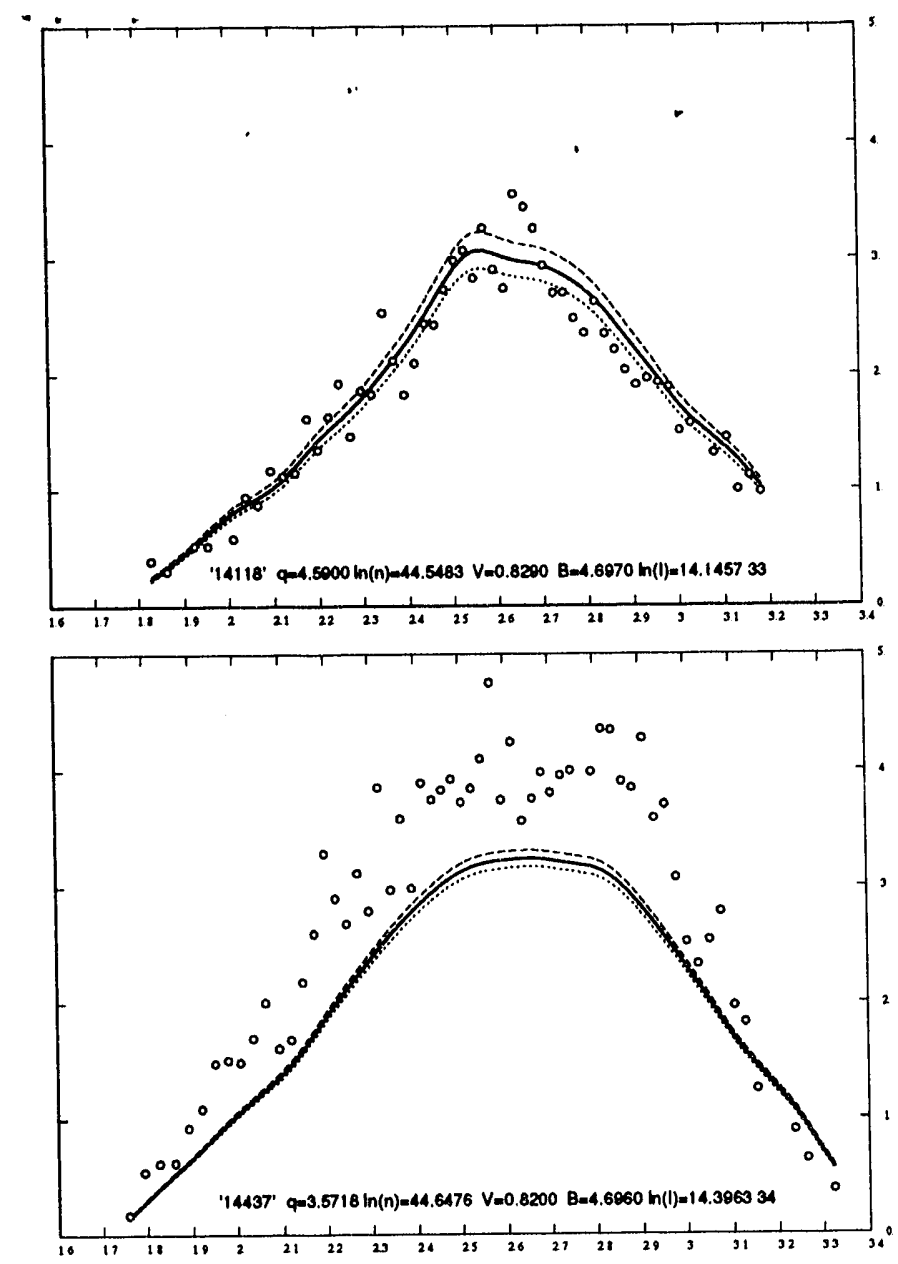

Figure $3 e$
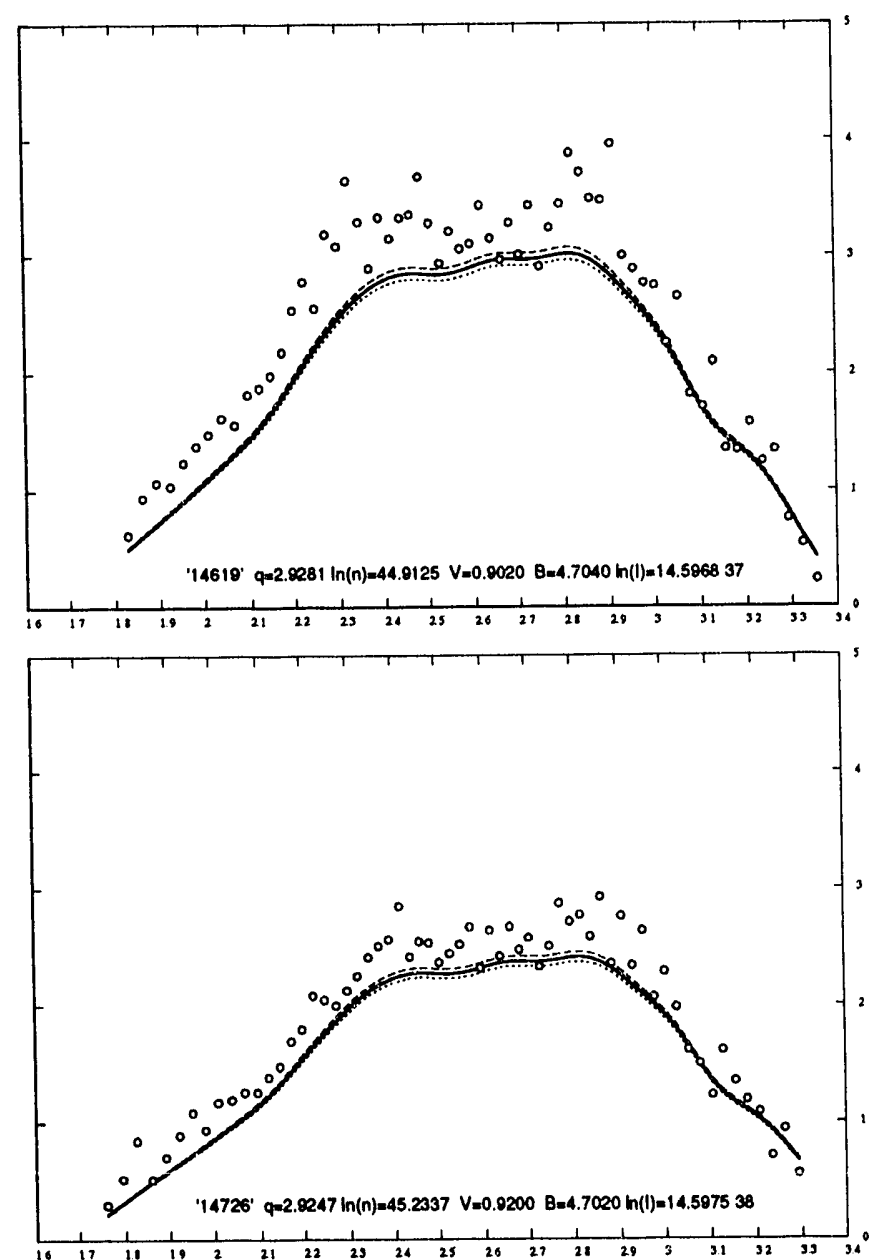
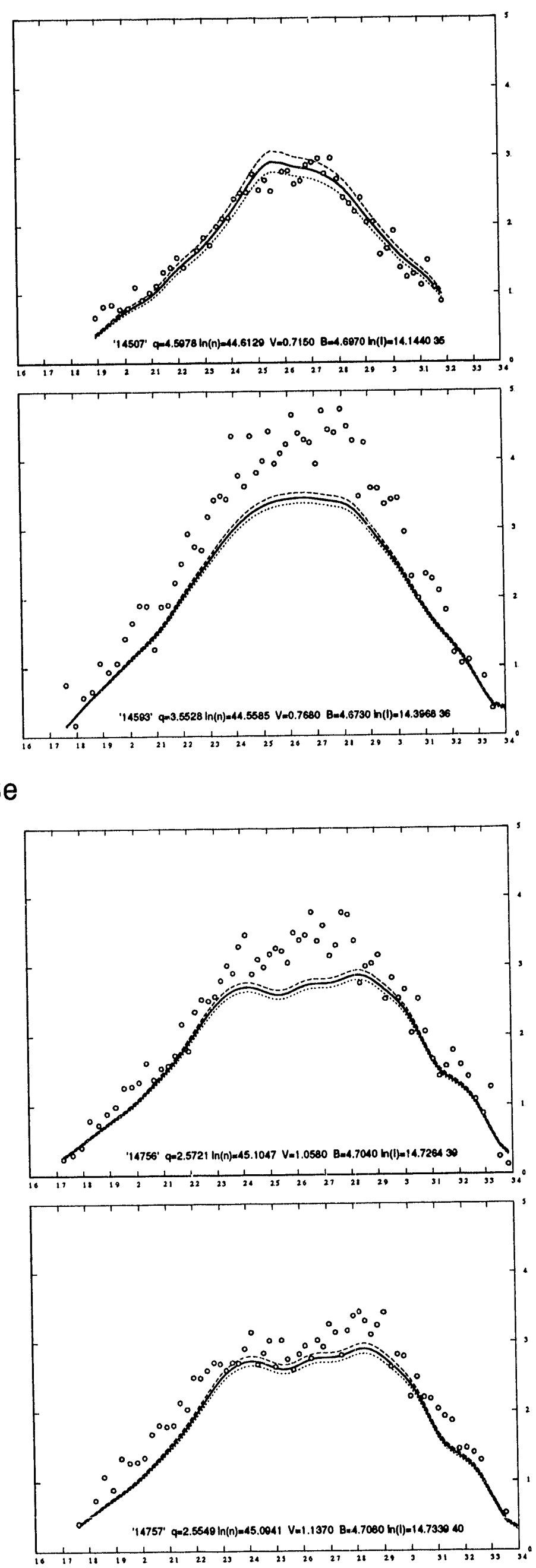

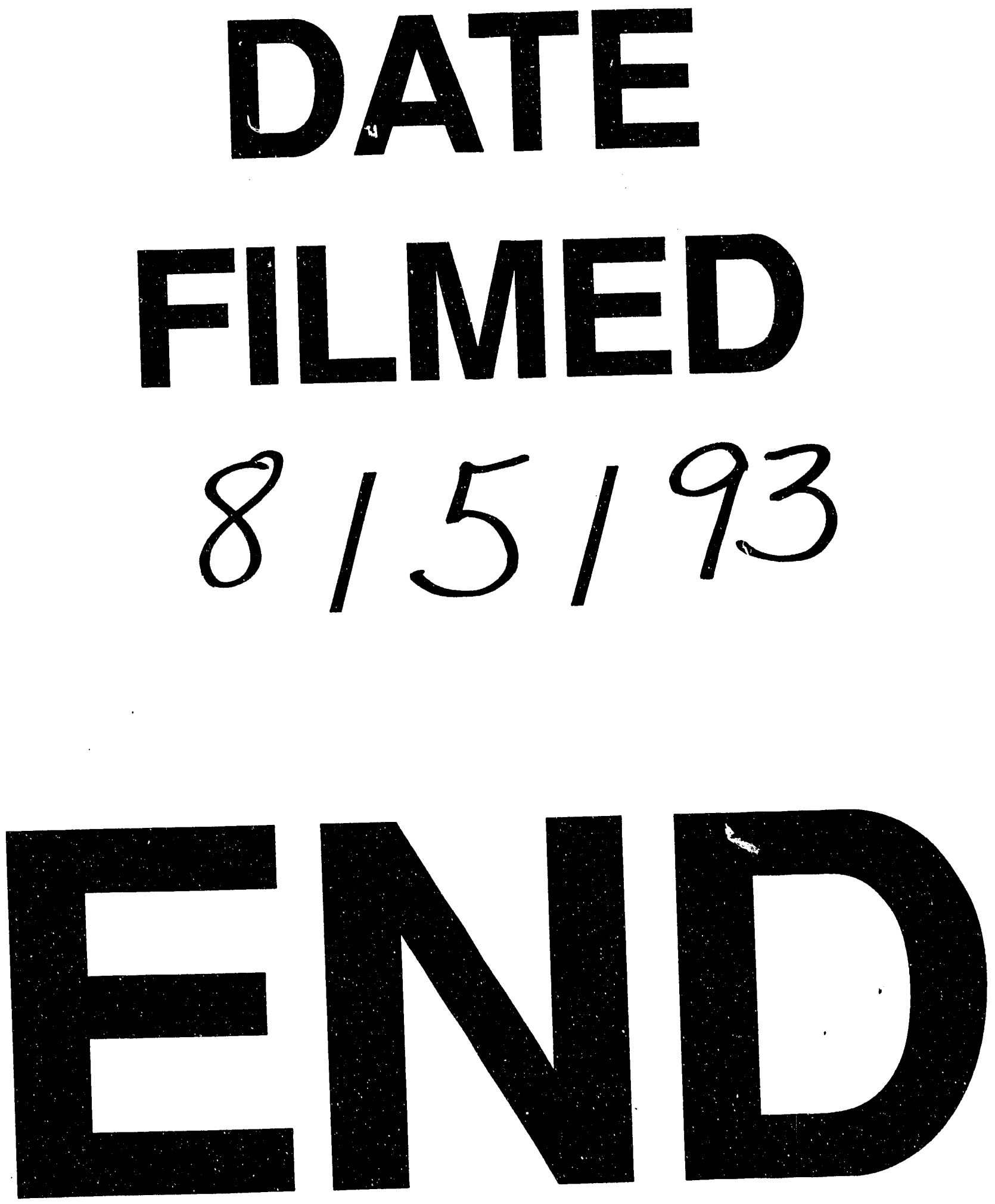
. 